\title{
Educação não formal: história e crítica de uma forma social
}

\author{
Carolina Catini ${ }^{1}$ \\ ORCID: 0000-0001-5568-9974
}

\section{Resumo}

0 presente artigo apresenta uma pesquisa que tomou como hipótese uma interpretação crítica da história da educação não formal no Brasil, que aborda seu surgimento ligado a um projeto conservador para mitigar a força da educação popular no período da Ditadura Civil Militar. A investigação partiu de tais indícios e de uma proposta metodológica da sociologia política que se refere ao estudo das formas sociais hegemônicas para buscar elos de tal processo na história da educação não formal. A exposição que segue apresenta os resultados de uma investigação com base em pesquisa bibliográfica e documental. De um lado, tal processo é especificado pela substituição dos programas de educação de adultos desenvolvidos no início dos anos 1960, no bojo dos movimentos de cultura popular, que tinham Paulo Freire como referência, pela instituição do Mobral (Movimento Brasileiro de Alfabetização). De outro lado, o exame dos documentos da UNESCO, sobretudo a partir dos textos de Philip Coombs, considerado o pioneiro no uso do termo educação não formal, como recomendação para superação da crise na educação. Em ambos os movimentos, o nacional e internacional, é possível identificar a gênese dessa forma social que se configura pela associação entre Estado, entidades privadas e sociedade civil. Essa forma altera os agentes e as finalidades de uma educação voltada às classes populares. A prevalência dessa forma social apresenta-se em outros momentos-chave da história da educação não formal, sobretudo na década de 1990, com o crescimento do terceiro setor, das ONGs e das fundações e institutos empresariais.

\section{Palavras-chave}

Educação não formal - Educação popular - História - Hegemonia - Forma social.

1- Universidade Estadual de Campinas (Unicamp) - Campinas, SP. Contato: ccatini@unicamp.br. 


\section{Non-formal education: history and criticism of a social form*}

\section{Abstract}

This article presents a research that considered as a hypothesis a critical interpretation of the history of non-formal education in Brazil. Here we address its emergence linked to a conservative project to mitigate the strength of popular education during the period of the military dictatorship. The investigation started from such indications and from a methodological proposal of political sociology that refers to the study of hegemonic social forms to search for links of such process in the history of non-formal education. The following presentation discusses the results of an investigation based on bibliographic and documental research. On the one hand, this process is specified by the replacement of adult education programs developed in the early 1960s, amid popular culture movements, which had Paulo Freire as a reference, by the institution of Mobral (Brazilian Movement of Literation). On the other hand, the examination of UNESCO's documents, especially from the texts of Philip Coombs, considered the pioneer in the use of the term nonformal education, as a recommendation to overcoming a crisis in education. In both movements, national and international, it is possible to identify the genesis of this social form configured by the association between the State, private entities, and civil society. This form changes the agents and purposes of an education aimed at the popular classes. The prevalence of this social form appears at other key moments in the history of nonformal education, especially in the 1990s, with the growth of the third sector, NGOs and business foundations and institutes.

\section{Keywords}

Non-formal education - Popular education - History - Hegemony - Social form.

\section{Introdução}

A aproximação inicial com o termo educação não formal pode abranger um conjunto incomensurável de práticas educacionais (GHANEM, 2008). Por vezes, na produção teórica, é aventada uma diversidade tão grande de atividades que sua unidade e singularidade apenas mobiliza uma noção difusa de forma educativa distinta da escolarizada, e não um conceito ou definição precisa. Tal amplitude contempla práticas que vão desde a formação política em sindicatos e partidos políticos, até a educação infantil ou de jovens em Organizações Não Governamentais (ONGs) no contraturno escolar, passando por vivências de arte-educação, de divulgação científica em museus, pela educação popular, pela transmissão de conhecimentos que se referem à resistência indígena e quilombola, 
pela educação em movimentos sociais, por manifestações culturais e artísticas de toda ordem etc.

A despeito dos esforços envidados para delimitar essa linha de investigação, discernindo entre educação formal (escolar), educação não formal (atividades intencionais e sistemáticas de formação com conteúdo diverso) e educação informal (processos de aprendizado não intencionais que ocorrem em diversas situações sociais), tal qual fazem Gohn (2006), Afonso (2001), Aroeira Garcia (2007), um grau de indeterminação permanece e apresenta-se como dificuldade para apreensão teórica de tal objeto de estudo. Para Marques e Freitas (2017), o termo educação não formal é polissêmico e sua definição não é estanque. Isso reforça problemas metodológicos que se impõem ainda quando se considera a finalidade das propostas de educação não formal. Para Trilla (2003), a descrição e a amplitude da educação não formal revelam que, em suas múltiplas orientações, existe a tendência de não se diferenciar fortemente das formas hegemônicas, podendo configurar-se como prática transformadora, mas também "tão classista, alienante, burocrática, ineficaz, onerosa, obsoleta, manipuladora, estereotipada, uniformizadora etc. como pode ser a formal" (TRILLA, 2003, p. 143). Assim, à amplitude do objeto de estudo e à especificidade de cada tipo de prática, somam-se dificuldades concernentes às disputas de significado do uso do termo em contextos distintos. Essa imprecisão impõe a superação de problemas metodológicos para o estudo da educação não formal.

Diante desse quadro, para nós, a proposta metodológica feita por Carlos Alberto Torres (1992) no início dos anos parece continuar válida como forma de apreensão consistente da educação não formal como objeto de estudo. A partir dos fundamentos da sociologia política, o autor sugere que uma das principais tarefas intelectuais para delimitação das questões investigativas da educação não formal deve referir-se ao estudo da identificação das tendências ascendentes e minoritárias de concepções e modos de organização das práticas. Isso porque, de acordo com o autor, "o limiar entre as teorias e ideologias não só é muito tênue como, nesse campo, às vezes não existe” (TORRES, 1992, p. 220), e o caminho para desfazer abstrações teóricas e produções teóricas ideológicas diz respeito a uma análise do processo histórico de uma prática e de um campo de investigação. Para o autor, "a educação não formal deve enfrentar o desafio da teoria” (TORRES, 1992, p. 220), uma vez que sua configuração como um campo "subteorizado" não significa que seja isenta de disputas políticas de sentidos, ou marcada pela ausência de diferentes racionalidades que orientam as práticas. As tendências ascendentes no interior de um campo, ou a construção da hegemonia de uma forma social, segundo Torres (1992), devem ser estudadas a partir da identificação dos principais agentes e das relações concretas de dominação polítíca, econômica e social, suas práticas, seu financiamento e suas relações com o Estado. Para o autor, tais elementos circunscrevem uma racionalidade orientadora das finalidades da educação não formal em conjunto.

0 presente artigo persegue como hipótese uma interpretação que Carlos Rodrigues Brandão (1984) apresentou acerca da gênese da educação não formal, em um importante seminário que debateu os dilemas da educação popular ao final do Regime Militar². Na análise

2- A importância desse texto é singular por ser o único que apresenta a educação não formal como confronto com a educação popular de cunho transformador, mesmo que a transformação se apresente em suas grandes nuances de radicalidades entre projetos revolucionários e 
do autor, a educação não formal surgiu como estratégia estatal de conversão da orientação política da educação para as classes populares, durante a ditadura militar brasileira, eliminando ou neutralizando a força do processo político da educação popular vinculada às lutas e organização populares com pautas de interesse de trabalhadores e trabalhadoras.

Para apresentar essa pesquisa, foi preciso situar brevemente o significado político da prática de educação polular em curso antes do Golpe Militar para, em seguida, apresentar a educação não formal. Isso foi feito pelo estudo da instituição do Mobral (Movimento Brasileiro de Alfabetização) em substituição aos programas de educação popular vinculados às práticas de Paulo Freire, que se deu pela associação entre Estado, entidades privadas ligadas ao empresariado e entidades ligadas à sociedade civil, naquele momento representadas por associações de moradores ou entidades de organização de trabalhadores e trabalhadoras. Embora a orientação política e as práticas consideradas como educação não formal tenham se multiplicado em uma grande variedade, a pesquisa localiza nesse momento o surgimento de uma forma social que se tornou a forma hegemônica. A pesquisa buscou também o uso do termo em documentos e legislação do período e as evidências mais relevantes das orientações para a difusão dessa então nova forma social. Tais evidências, que apresentamos na segunda parte deste texto, foram encontradas nas recomendações da UNESCO (Organização das Nações Unidas para a Educação, a Ciência e a Cultura) da década de 1960, sobretudo por meio da obra de um dos porta-vozes da organização internacional naquele momento, Phillip Coombs. Na terceira parte, analisamos a hegemonização dessa forma social na história da educação não formal, com o resumo de três modelos de educação para as classes populares, configurados por Brandão ao final da ditadura, seguida da tratativa de alguns momentos-chave da história da educação não formal, sobretudo o momento de crescimento do papel das ONGs e do terceiro setor nos anos 1990, cuja importância é constatada pela posição que passam a ocupar nos documentos de políticas sociais, de educação e na bibliografia. Desse modo, podemos observar a permanência de estruturas criadas no período autoritário bem como a produção de uma formal social hegemônica da educação não formal ligada ao controle da educação das classes populares pelas classes dominantes.

\section{A educação da classe popular em disputa}

Há uma confluência nas interpretações recentes que localizam o surgimento da educação não formal no Brasil na década de 1960, impulsionado pelo crescimento da importância da educação de adultos ou da educação popular fora da escola ou dos sistemas formais. A partir dessa mesma bibliografia, a trajetória seguiria um desenvolvimento até a sua ampliação para a educação de crianças, jovens e adultos, no interior de uma verdadeira explosão de iniciativas da sociedade civil, capitaneadas sobretudo por organizações não governamentais, em especial a partir dos anos 1990, e que se expandiria até os dias atuais, ampliando vertiginosamente as práticas associadas à educação não formal (GOHN, 1998;

reformistas.0 debate ocorreu em 1982 no Seminário sobre Educação popular promovido pelo IBRADES/Centro João XXIII no Rio de Janeiro entre 29 de novembro e 2 de dezembro. Os textos-base do seminário foram publicados em Paiva (1984). 
2006; 2009; AROEIRA GARCIA, 2007, 2008, 2015; PARK; FERNANDES; CARNICEL, 2007; SIMSON; PARK; FERNANDES, 2001).

Tal percurso histórico, no entanto, não pode ser lido de maneira linear, como resultado de um progresso de formas de educação alternativas ou não escolares, pois referem-se a princípios, concepções e práticas distintas. A leitura crítica aqui apresentada trata de um momento de inflexão da passagem da educação popular para a educação não formal, que se refere a um processo de açambarcamento das práticas de educação voltadas às classes populares por instituições das classes dirigentes que, por diversos mecanismos, logram subsumir a forma e o conteúdo da educação não escolar aos seus interesses.

Vale dizer, de saída, que a educação não formal, no Brasil, se dirige à classe popular (AROEIRA GARCIA, 2008) e um dos elementos que assim circunscrevem a denominação está relacionado aos vínculos e marcas estabelecidos historicamente na trajetória de práticas de educação não escolar desde seu surgimento, mas também à forte relação que estabelece mais recentemente com a assistência social e à capacitação para o trabalho, bem como toda uma gama de atividades relacionadas à necessidade de fomentar atividades educativas voltadas para trabalhadoras, trabalhores e seus filhos.

A educação de adultos no Brasil ganhou expressão por meio de campanhas de alfabetização, que no Brasil tiveram início nas décadas de 1940 e 1950. É, no entanto, apenas na década de 1960, com o ganho de expressividade das práticas de educação popular, que tal campo de atuação se alçou à condição de detentor de uma metodologia "que passou a direcionar diversas práticas de educação de adultos, organizadas por distintos atores, com graus variados de ligação com o aparato governamental” (DI PIERO; JÓIA; RIBEIR0, 2001, p. 60). Nos primeiros anos da década de 1960, as exitosas experiências de alfabetização de trabalhadores e trabalhadoras rurais organizadas por Paulo Freire, tanto no Rio Grande do Norte, quanto em Pernambuco, ou em Natal, efetivaram aquilo que os governos e elites nacionais declaravam impossível: uma prática que poderia se desenhar como uma solução para o gigante analfabetismo, que excluía mais de cinquenta por cento da população trabalhadora brasileira (FREIRE, 2006). Além do que esses dados diziam sobre a desigualdade social, Paulo Freire destaca o papel da alfabetização na democratização de uma sociedade em pleno processo de mudança, além da possibilidade, a partir da alfabetização, da própria participação política pelo voto em um período de disputas entre projetos nacionais (FREIRE, 2006).

Além de alfabetizar, a educação popular criticava, na prática, o que havia de antipopular no elitista sistema educacional brasileiro, que, além de ser restrito na oferta de vagas, operava em uma relação antidiaólogica e bancária, isto é, se dava por um método tradicional de um professor que ensina e dos alunos que aprendem, estabelecendo uma constante negação dos conhecimentos populares e orais em benefício de uma cultura enciclopédica de transmissão de conteúdos escolares desercarnados de contexto e significação para trabalhadores e trabalhadoras. A alfabetização proposta por Freire aliava, portanto, em uma mesma ação educativa, a crítica da educação bancária com uma interpretação crítica da trajetória antidemocrática brasileira, abrindo meios para formas de participação política popular. 
Em seu método, pulsa a noção de que “a miséria e seu cimento, o analfabetismo, não são acidentes ou resíduo, mas parte integrada no movimento político da dominação do capital" (SCHWARZ, 1978, p. 69). Na interpretação de Schwarz (1978), embora a prática se desenvolvesse no bojo de um programa cristão e reformista do governo Miguel Arraes, em Pernambuco, a atmosfera criada pela capilaridade e inventividade do Movimento de Cultura Popular (MCP) nos anos anteriores tinha efeitos que ultrapassavam os limites eleitorais e de contenção da marginalidade das massas. Em uma movimentação entre estudantes universitários, trabalhadores, ligas camponesas e movimento de cultura popular, a prática da educação popular expandida por todo Brasil pelo Movimento de Educação de Base (MEB), ligado à União Nacional dos Estudantes (UNE), também continha elementos que escapavam ao controle estatal pela sua descentralização e vinculação com as lutas diretas. "Durante 12 meses foram criados 1.300 sindicatos rurais", conta Weffort (2006, p. 18), nos primeiros anos da década de 1960 no nordeste. Essa força política expressa-se nas "grandes greves de trabalhadores rurais de Pernambuco no ano de 1963, a primeira com 85.000 grevistas e a segunda com 230.000” (WEFFORT, 2006, p. 18).

Paulo Freire pensava o ascenso das lutas populares que estava em curso como processo de transitividade para uma sociedade democrática; sua simpatia à rebelião estava, em suas palavras, "somada a um profundo senso de responsabilidade" que devia passar “da rebelião em inserção", experimentando a via democrática pela participação efetiva sobre a construção dos destinos de onde se está inserido: a escola, o bairro, a igreja, o sindicato, a empresa (FREIRE, 2006, p. 100). Rapidamente, Paulo Freire foi convidado para coordenar o Programa Nacional de Alfabetização e Cultura no governo João Goulart. Se o programa tivesse sido cumprido, em 1964 estariam "funcionando mais de vinte mil Círculos de Cultura em todo o país” (FREIRE, 2006, p. 128). No momento, portanto, em que a prática estava em vias de tornar-se uma política educacional nacional no interior dos movimentos de reformas de base foi duramente reprimida pelo Golpe Militar, com a prisão e posterior exílio de sua principal referência, em conjunto com a dura repressão aos movimentos populares em todo Brasil.

Foi, nesse mesmo período, que se iniciou um processo de inflexão na educação voltada aos trabalhadores, somente encerrado nos fins dos anos 1980 e início dos anos 1990. Trata-se de um processo de desindentificação da educação de adultos com a formação política associada à militância e ao esboço da forma social da educação não formal no Brasil. Vejamos.

0 governo militar arquitetou, nos fins dos anos 1960, e colocou em prática, em 1971, o que seria a resposta militar ao vazio criado pela extinção do programa de alfabetização coordenado por Paulo Freire. Conhecido como Mobral - que curiosamente carrega no nome a palavra movimento: o Movimento Brasileiro de Alfabetização - foi amplamente propagandeado pelo governo militar em bilhetes de casas lotéricas, revistas, jornais e televisão. Os chamados apelavam à participação da população ${ }^{3}$ : "Pelo amor de Deus, ensine alguém a ler: se você é prefeito, empresário, estudante, você pode ajudar.

3- Todas as propagandas citadas aqui podem ser encontradas numa pesquisa simples na internet de imagens do Mobral. Algumas delas podem ser conferidas, por exemplo, aqui: http://cultura.culturamix.com/curiosidades/Mobral-movimento-brasileiro-para-a-alfabetizacao. Acesso em: 10 abr. 2019. 
Se você dirige um sindicato, uma organização religiosa, uma associação, você pode ajudar. Então ajude”. A convocatória igualmente dirigida a representantes do Estado, do empresariado, da igreja, do sindicato e dos estudantes (como se grupos que representam interesses distintos, e muitas vezes opostos, pudessem orientar suas práticas num sentido comum) é uma das marcas da instituição da substituição, e não continuidade, da educação popular pela educação não formal no Brasil. A busca por uma imagem neutra e benfeitora da alfabetização aos poucos se traduz numa política delineada desde cima que busca deliberadamente confundir e mesclar agentes da educação para o povo como prática compensatória e não mais contestatória.

A divulgação do Mobral também se dirige a uma determinada classe e coloca um sentido assistencial e que individualiza a prática que Paulo Freire tomava como ato coletivo: "Ensine o primeiro analfabeto que encontrar: a empregada, o jardineiro, a irmã da costureira, a costureira, a manicure. Com o material de alfabetização do Mobral, você ensina qualquer pessoa a ler e escrever em 90 dias”. A mais emblemática das propagandas do Mobral, no entanto, talvez seja a que se dirige diretamente aos empresários e inverte o sinal da educação de adultos que se praticava até então, colocando-a claramente a serviço da classe dominante. Na contracapa de uma revista da Editora Abril, com uma foto de um magnata sorrindo à la Poderoso Chefão, se lê:

Figura 1- contracapa de uma revista da Editora Abril

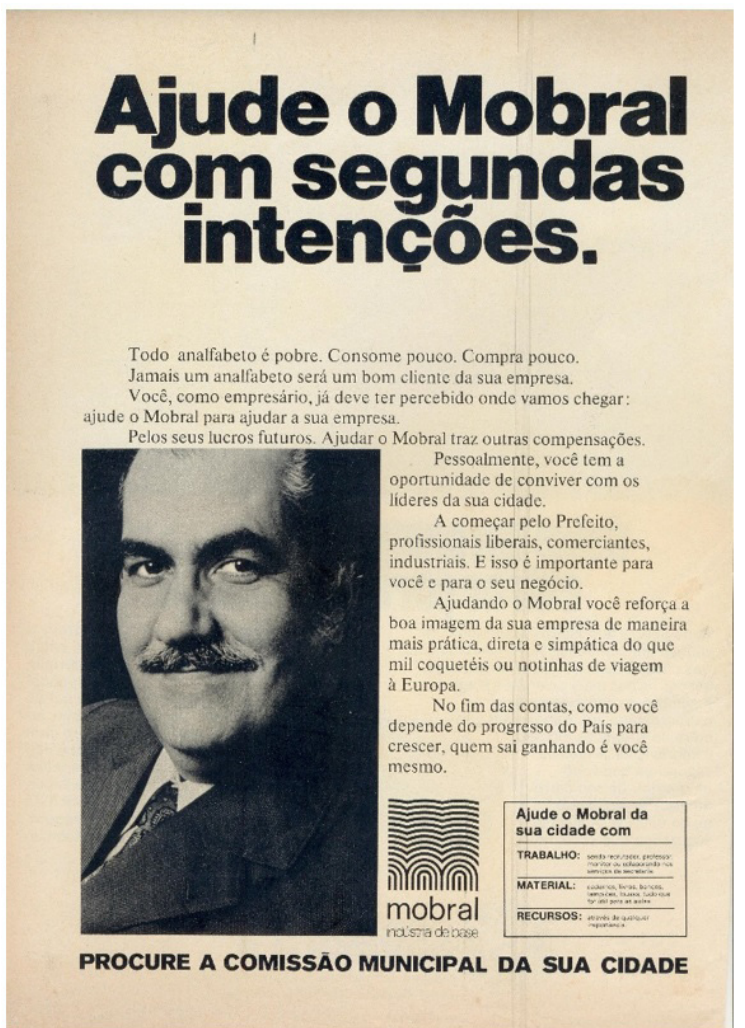

Ajude o Mobral com segundas intenções. Todo analfabeto é pobre, consome pouco, compra pouco. Jamais um analfabeto será um bom cliente da sua empresa. Você, como empresário, já deve ter percebido onde vamos chegar: ajude o Mobral para ajudar a sua empresa. Pelos seus lucros futuros. Ajudar o Mobral traz outras compensações. Pessoalmente, você tem a oportunidade de conviver com os líderes de sua cidade. A começar pelo prefeito, profissionais liberais, comerciantes, industriais. Ajudando o Mobral você reforça a boa imagem de sua empresa de forma mais prática, direta e simpática do que mil coquetéis ou notinhas de viagem à Europa. No fim das contas, como você depende do progresso do País para crescer, quem sai ganhando é você mesmo. (MOBRAL, material de divulgação).

Fonte: Acervo Digital da Revista Veja, em 4 de setembro de 1974, p. 108. 
A ausência de disfarce acerca dos reais beneficiários do programa de alfabetização popular presente na propaganda governamental, direcionada aos dirigentes econômicos, dispensaria comentários não fosse a associação com a articulação mais orgânica do empresariado com o Estado no Regime Militar nessa fase de endurecimento, perseguição, torturas etc. Não se pode perder de vista que a substituição da educação popular pela educação não formal ganhava forma em meio à violência estatal e empresarial radical instaurada no período. 0 "terror de um Estado delinquente", nas palavras de Paulo Arantes, permitiu que irrompesse, desde então, uma "era da impunidade" com prolongamentos históricos de formas de dominação, evidenciando que "essa tecnologia de poder e governo também não pode mais ser desinventada” (ARANTES, 2014, p. 284). É preciso, portanto, observar os elementos que se tornaram permanentes desde a ruptura da organização popular provocada pela ditadura. Para nossa investigação, além da violência da gestão estatal para diversos tipos de subordinação e apassivamento das lutas sociais, é fundamental destacar o aspecto que remete à articulação entre Estado, sociedade civil e empresariado pela introdução de uma noção semelhante à ideia da responsabilidade social, que passa a aliar, mais adiante - com clareza a partir dos nos 1990, a propaganda da imagem do socialmente responsável com o controle de projetos sociais voltados às camadas mais pobres da população, efetivada pela transferência da execução de serviços e recursos estatatais para o setor privado.

Não obstante o Mobral tenha sido um fracasso nos intentos alfabetizadores - e talvez, por isso mesmo, pelo vazio de sua significância para a alteração da realidade social pela educação -, sua forma social, em contraposição, tornou-se modus operandi válido para o empresariado (em conluio com o Estado autoritário), na medida em que efetivamente mobilizou muitas pessoas, entidades, associações, em função do interesse econômico e político de dominação social, alterando por completo a imagem da educação de adultos associada à formação política.

Vale registrar ainda que, em 1971, o Ministério de Educação e Cultura enviou às prefeituras de todo país o "documento base de implantação do MOBRAL". Após uma breve introdução e apresentação do programa, há um item intitulado "o encaminhamento do problema de alfabetização pelo atual MOBRAL" que inicia com os dizeres: "0 analfabeto não é apenas do Governo; é de toda comunidade", ao que conclui que "todos são responsáveis, principalmente os que gozaram dos privilégios da escola" (BRASIL, MEC, 1971, n.p). A propaganda, anteriormente citada, reproduz o texto do primeiro tópico desse documento que se refere à "iniciativa privada":

Houve uma preocupação de parte do MEC no sentido que coubesse à iniciativa privada, a Direção do MOBRAL, nos seus vários níveis: Nacional, Regional e Municipal. A iniciativa privada deve visar a alfabetização, não apenas como procedimento patriótico, mas como investimento. Alfabetização + semiqualificação = maior rendimento, melhor salário, melhor nível social, um gerador de riquezas, um melhor consumidor. Queremos convencer o empresário brasileiro de que a expansão do seu mercado interno está em função desse padrão social que se pretende elevar pela Alfabetização Funcional. (BRASIL, MEC, 1971, n.p.). 
Não apenas fica evidente a captura do processo de formação de adultos pela associação de parceria entre o público e o privado, que é o próprio germe do terceiro setor ou das Fundações Empresariais voltadas a trabalhos sociais, mas também um modo de operacionalizar a noção de produtividade pela reificação de cada indivíduo formado pela educação não escolar, bastante identificada com a teoria do capital humano. A chance de que cada trabalhador e trabalhadora se torne peça de um mecanismo rentável, como força de trabalho inserida na produção e no consumo, também desenha a lógica de um direito social que funciona como investimento econômico, uma espécie de especulação de um futuro rentável.

Já do ponto de vista político, esse processo remonta à própria gênese da educação não formal no Brasil. Para Carlos Rodrigues Brandão (1984), militante e educador popular nas décadas de 1960, 1970 e 1980, é no desenvolvimento de formas de educação voltadas para setores populares, durante o período autoritário, que se criou no Brasil e em outros países do continente uma oposição evidente "dentro do domínio da 'educação com setores populares', entre uma 'educação não formal' e uma 'educação popular”. Se essa última "coloca o trabalho do educador a serviço de projetos políticos de libertação das classes populares", ela faz o "contrário do que projeta realizar a educação não formal", uma vez que essa foi "gerada pelo poder do Estado ou por agências dominantes e destinadas à domesticação e controle das classes populares” (BRANDÃO, 1984, p. 179, grifos meus). É preciso observar mais detidamente esse processo.

\section{A educação não formal na crise mundial da educação}

É preciso aqui incluir uma mirada internacional às influências para o surgimento e o crescimento da educação não formal no Brasil. Tanto a bibliografia nacional (AROEIRA GARCIA, 2008; AROEIRA GARCIA, 2015; SIMSON; PARK; SIEIRO FERNANDES, 2001) quanto a internacional (PALHARES, 2007) oferecem indícios de uma relação entre o surgimento da educação não formal e a ação de organismos internacionais.

Tais estudos mencionam a articulação do uso do termo educação não formal em uma conferência sobre a Crise Mundial da Educação, organizado por Coombs em 1967 no estado da Vírginia, Estados Unidos, e que reuniu líderanças educacionais de diversos países. 0 Brasil esteve representado por Anísio Teixeira. Na verdade, o documento síntese do congresso não menciona o termo e só há possibilidade de vinculação com a educação não formal quando observamos a sugestão de que os países reexaminem suas leis fiscais "a fim de estimular o fluxo de recursos privados para fins educacionais" (UNESCO, 1967, p. 06). De todo modo, no ano seguinte, o autor lança um livro com o mesmo nome do congresso e nele apresenta a educação não formal como possivel aliada para combater a incapacidade de atender às demandas sociais pelos sistemas formais de ensino. Sua análise esquemática de dados mereceria uma interpretação crítica mais detida, assim como sua adesão às Teorias do Capital Humano em formulações como: “o ensino é uma indústria de produção de massa e exige trabalho intensivo" ou, ainda, que "ensino é produtor e consumidor de mão de obra de alto nível para servir consumidores de mão de obra" (COOMBS, 1976, p. 60). Para o autor, a educação difere-se de uma loja de departamentos: 
[...] contudo, em comum com todos os outros empreendimentos de produção, um conjunto de entradas (inputs) que são submetidas a um processo destinado a alcançar certas saídas (outputs) que devem levar à satisfação dos objetivos. (COOMBS, 1976, p. 28, grifos do autor).

A análise da crise da educação, mote da conferência, é feita mediante a leitura do crescimento vertiginoso dos sistemas de ensino formais na década de 1950, da análise de gastos em cada país e da eficácia e da eficiência medidos pelo padrão de formação de mão de obra e continuidade dos estudos acadêmicos. Os desajustes causados pelo aumento de reivindicação popular pelo ensino e a defasagem no atendimento à demanda, em conjunto com a escassez de recursos e a inércia dos sistemas escolares e da própria sociedade - que segundo o autor resiste às modernizações por carregarem "o pesado fardo das atitudes tradicionais" (COOMBS, 1976, p. 21) - coloca empecilhos para as mudanças necessárias nos sistemas de ensino. Para tanto, seria necessário alterar a formação docente, pois os professores "estão no âmago da crise educacional" (COOMBS, 1976, p. 59). Com isso, o autor adentra a análise da educação não escolar ou educação permanente - inaugurando o uso do termo educação não formal como um campo de ação - por ela apresentar maior sucesso em seus objetivos, associando diversos segmentos sociais que não apenas os especialistas em educação.

Partindo de um reconhecimento de que existe uma espécie de sistema paralelo de educação não formal, que é de difícil apreensão por estar fora dos processos de planejamento e pelo fato de ser realizada por "dezenas de entidades públicas e privadas" e que aparecem e desparecem com muita fluidez (COOMBS, 1976, p. 198), o autor nota que há uma distinção entre países centrais e desenvolvidos e os países pobres, subdesenvolvidos e socialistas. Nos Estados Unidos, por exemplo, havia grande rede de educação permanente, idenficadas por três origens:

[...] um era mantido pelas empresas particulares, o segundo pelas corporações militares, e o terceiro compreendia uma miscelânea de atividades educacionais patrocinadas por organizações voluntárias. (COOMBS, 1976, p. 200).

Na URSS (União das Repúblicas Socialistas Soviéticas) e outros países socialistas, obtinham-se "resultados notáveis" justamente por conseguir aliar os sistemas formais e não formais e relacionar de maneira intima trabalho e estudos (COOMBS, 1976, p. 201), enquanto que, nos países pobres, a educação não formal seria eficaz por proporcionar:

[...] a um grande número de agricultores, operários, pequenos comerciantes e outras pessoas que nunca entraram em uma sala de aula um conjunto de conhecimentos e habilidades a serem utilizadas em benefício de seu próprio desenvolvimento e de seu país. (COOBMS, 1976, p. 203).

Para ele, era "claro que nos anos futuros o ensino não formal precisará ter como objetivo principal a formação de agricultores e de líderes rurais (inovadores e empreendedores de diversos tipos)" (COOMBS, 1976, p. 204, grifos meus).

Nesse período, Coombs criou o Institito de Planejamento Educacional da UNESCO, tendo trabalhado antes na Secretaria de Educação dos EUA, no governo Kennedy, e depois 
na USAID (United States Agency for International Development), que teve muita influência na educação brasileira no período ditatorial, em que se estabeleceram as parcerias MECUSAID para as reformas de ensino formal. E, como vimos, também a educação não formal passou a fazer parte das sugestões para melhoria da qualidade educacional nos países periféricos. Coombs finaliza suas considerações acerca do papel da educação não formal na superação da crise da educação sugerindo dinamizar a pesquisa nesse campo de importância vital. Deve-se conhecer, portanto, o que já existe e incluí-la no planejamento educacional para que, com isso, aprimore-se a relação entre o ensino formal e não-formal e se possa "demolir o muro que os separa, e promover entre os dois uma melhor divisão do trabalho" (COOMBS, 1976, p. 206).

Em suma, a introdução da designação da educação não formal no léxico educacional tem sua gênese de fora para dentro, vindo de fora da educação escolar e do território nacional. Ela tem por objetivo criar um novo campo de investigação das práticas com setores populares para apreender como se dá a geração de resultados produzidos com recursos escassos com objetivo de subordinar seu desenvolvimento à planificação educacional para o desenvolvimento das nações periféricas (PALHARES, 2007).

É digno de nota o relato de Paulo Freire de que recebeu uma visita de Coombs, dez anos após o lançamento de Crise mundial da educação, surpreso com a influência de Freire nas mudanças em curso na educação em diversos países pobres, construída em seu tempo de exílio e passagens por países da África e da América Latina. Na conversa, relatada em livro, Freire diz não concordar que tenha havido uma crise na educação, mas, sim, uma crise no sistema (FREIRE; GUIMARÃES, 2014).

Em entrevista concedida ao jornal Folha de São Paulo, em 29 de maio de 1994, Paulo Freire menciona o quanto foi criticado "por alguns elementos da esquerda, que me pensaram pervertido pela Aliança para o Progresso" (FREIRE, 1994) para realizar a alfabetização em Angicos. Trata-se de um programa norte-americano que financiou, junto com o governo do Rio Grande do Norte, a alfabetização em Angicos em 1963 (GERMANO, 1993). E vale citar a entrevista aqui para lembrar que além de Paulo Freire - que se tornou símbolo da educação popular - havia, naquele contexto, muitos outros grupos, inclusive com e perspectivas mais radicais no âmbito da relação entre Estado e financiadores, além de objetivos distintos no que se refere aos graus de mudanças sociais pretendidas ou mesmo ao que se vislumbrava como participação popular. Nessa reportagem da Folha, as entrevistadoras Marilene Felinto e Mônica Rodrigues da Costa perguntam: "Seu método é mais importante por ter fundado uma filosofia da educação no Brasil ou pela aplicação concreta que teve?", ao que Paulo Freire responde:

Todas essas coisas são válidas. Um fato curioso quanto à aplicação concreta no Brasil é, por exemplo, o Mobral nascer para negar meu método, para silenciar meu discurso, mas ter trazido para dentro de seu quadro de professores jovens que tinham trabalhado com o método Paulo Freire. (FREIRE, 1994, n.p.).

Embora o termo educação não formal não seja utilizado nos documentos oficiais brasileiros do período na ditadura, nem mesmo para classicar o Mobral, parece que a 
associação feita por Carlos Rodrigues Brandão (1984) torna tal processo inteligível, sobretudo se considerarmos a forte influência de organismos internacionais na organização da educação dos países latino-americanos sob governos autoritários. Para ele, entre 1960 e 1980, produziu-se uma clara oposição entre educação popular e educação não formal, uma vez que, nesta última, mesclam-se diferentes agentes, espaços, financiadores, metodologias e objetivos com interesses antagônicos ao da rebeldia popular, profundamente marcados pelo conservadorismo, repressão e estancamento das lutas sociais pela ditadura.

Assim, Brandão propõe um estudo a partir da "incursão semântica do assunto" que "poderia revelar a direção de tendências", onde à direita estaria o uso da expressão educação não formal, no centro ficaria a expressão educação participante e, finalmente, “à esquerda do campo, associa-se a ideia de 'educação popular' a de projetos de horizonte socialista e condução popular e, em alguns casos, prefere-se a adoção pura e simples da fórmula “educação política”" (BRANDÃ0, 1984, p. 198, grifos meus).

\title{
A produção de uma forma hegemônica de educação das classes populares
}

\author{
Caçamos borboletas ou nos iludimos com as nossas palavras? \\ Não há escolas para o povo, companheiro; há escolas do povo ou há escolas do opressor \\ Há o MOBRAL e há os grupos locais das lutas populares, \\ Em qual dos lados ficamos, professor? \\ Há os cursos patronais de formação de mão de obra, há o Projeto Minerva, \\ os supletivos da TV Globo, \\ Os programas inócuos de Educação de Adultos \\ E as mentiras do Desenvolvimento de Comunidades \\ Do outro lado há momento de prática, movimentos, \\ Espaços populares e luta, avanços e recuos, procura de organização, \\ trajetória de trabalho e revisões. \\ Há grupos, gentes, frentes e agentes populares de luta e de cultura. \\ De um lado as escolas-prisões cheias de flores e recursos didáticos: \\ Armadilhas que transformam o homem em massa e o corpo em máquina. \\ Do outro lado as situações, companheiro, as estruturas, \\ as escolas, os instrumentos e os educadores direto da classe. \\ Carlos Rodrigues Brandão, 1980.
}

(Sexto trecho do poema "A cultura do povo e a educação popular")

A diversificação de modelos e agentes de educação de adultos das classes populares, para Brandão (1984), diluiu uma clareza de projetos antagônicos das classes capitalista e trabalhadora tal qual se podia observar no início dos anos 1960, embora no domínio da educação popular também se apresentassem concepções mais ou menos radicais na sua autonomia frente ao Estado: primeiro em relação ao reformismo, mas também ao vanguardismo dos movimentos, depois em relação à posição das organizações de esquerda frente ao Golpe Militar. Na prática, a dissolução da evidente dicotomia entre a educação 
não formal e a educação popular se deu com o crescimento de uma terceira via entre os dois campos nas décadas posteriores.

A educação não formal, que pode ser representada pelo Mobral em seu momento fundacional, é organizada pelo Estado em conjunto com empresas, voluntários e organizações da sociedade civil, e se dirige aos trabalhadores e trabalhadoras como indivíduos para uma "participação consumista" e subalterna: "produtivo no trabalho, subordinado na vida cotidiana, dócil na política” (BRANDÃO, 1984, p. 188). Em seu extremo oposto, estaria a educação popular, organizada por grupos e coletivos populares e dirigida a movimentos e organizações de trabalhadores e trabalhadores, voltada à produção do "poder popular" e fortalecimento da classe para um processo revolucionário de enfrentamento ao capitalismo (BRANDÃO, 1984, p. 188). Mas no "meio de campo" se encontraria o que Brandão denominou "educação participativa”, com fronteiras menos marcadas, podendo se direcionar mais para o conformismo ou para as necessidades de mudanças sociais de acordo com seu desenvolvimento prático, na interação entre comunidade e agentes educativos, que se diversificam, voltando-se para uma luta social de desenvolvimento comunitário local, "com vistas à produção do fortalecimento da sociedade civil e da conquista de modelos de sociedade politicamente participativas e economicamente desenvolvidas" (BRANDÃ0, 1984, p. 188) no interior de uma noção identicada pelo autor como "participação produtiva".

Se as formas descritas por Brandão contribuem para tornar inteligível modelos de educação voltadas para as classes populares, o dinamismo do processo social mescla tendências de maneira ainda mais complexa. Como vimos, Paulo Freire (1994) menciona que o Mobral deslocou para o interior de seu projeto educadores e educadoras formadas para os círculos de cultura. Mesmo Brandão (1984) admite que, por vezes, o vínculo com as lutas sociais, da associação de moradores ou sindicato rural com o qual empresários locais e prefeituras de municipios se relacionam acabam tornando a experiência um tanto mais democrática e participacionista do que o projeto militar previa desde o Ministério da Educação. As experiências de cunho revolucionário ficaram reduzidas a pequenos grupos isolados e, aos poucos, a insígnia democracia passa a predominar sobre as diversas experiências - mesmo naquelas patronais e empresariais, que passam a adotar o discurso predominante para propagandear suas práticas, o que aparece mais claramente com o enfraquecimento do autoritarismo estatal.

0 fato é que, durante o longo período de ditadura militar no Brasil, as experiências de educação popular que conseguiram se manter tiveram de se desenvolver na clandestinidade, diante da dificuldade de circulação e interação entre tais experiências. Apenas o processo de redemocratização mudaria esse quadro quando grupos passam a aparecer na ordem do dia, como registrara o estudo Quando novos personagens entram em cena, de Eder Sader (1980). Além das novas formas políticas tomadas pelo que denomina novo sindicalismo, o autor atenta para formas de organização em comunidades periféricas em experiências de vários tipos, inclusive educativas. Isso porque "os movimentos constituídos a partir de trabalhadores precários, de donas de casa, de favelados, tendo por base a "esfera da reprodução’, teriam de se apoiar em outras referências” (SADER, 1988, p. 195): 
Seus movimentos apoiaram-se em estruturas comunitárias, fundadas na solidariedade grupal. Excluídos de empregos estáveis, de direitos congregados, eles constituíram suas próprias referências. Apoiando-se na Igreja, encontraram tanto uma instituição poderosa em condições de proteger suas lutas quanto, principalmente, um discurso sobre a solidariedade e a justiça em nome dos quais as travaram. (SADER, 1988, p. 195).

No bojo da ascensão de novos movimentos sociais, sobretudo após as grandes greves operárias de 1978 e 1979 dos movimentos grevistas de professores e professoras no inícios dos anos 1980, e do aparecimento de formas associativas gestadas durante o período autoritário, desenvolveu-se, dentre educadores e educadoras populares, um acirrado debate do qual faz parte a posição crítica de Brandão que estamos trabalhando aqui, bem como de diversos outros educadores e educadoras populares, militantes da educação ou de organizações e movimentos sociais. Tratava-se de uma decisão a se tomar frente ao momento de redemocratização: apostar na continuidade de práticas não estatais ou em disputar as orientações políticas das práticas de educação com as classes populares por dentro do Estado.

Vanilda Paiva (1984) sintetiza o momento como um desafio colocado aos educadores e educadoras engajados que se referia à decisão de permanecer desenvolvendo o fortalecimento de práticas isoladas de educação popular bastante contextualizados e qualitativos, os quais "mais facilmente se desenvolve com inovações nos pequenos movimentos" (PAIVA, 1984, p. 37), ou envolver-se nos processos de democratização que poderiam alargar e envolver quantitativamente maior número de pessoas na educação tida como direito universal.

De acordo com a autora, reconhece-se a essa altura a limitação de práticas educativas da sociedade civil, ao mesmo tempo em que se constata, de modo geral, que o processo de democratização introduziria a possibilidade de transformar os aparelhos do Estado em instrumentos da luta política, por meio do crescimento da participação e do controle social. Com isso, venceu a proposta de conjugar as lutas, tentando "encontrar formas possíveis de articulação das pequenas instituições e de iniciativas da sociedade civil com o Estado" (PAIVA, 1984, p. 39).

Durante os anos 1980, muitos esforços voltam-se para as lutas em torno dos direitos humanos, para a construção das primeiras eleições democráticas, para a contrução de leis e de uma Constituição democráticas, para as lutas pelas mudanças no funcionamento das instituições públicas - dentre as quais a escola, envolvida em lutas econômicas pelas greves e políticas pela democratização da gestão e do acesso à escolarização pelas camadas populares, o que se dava no âmbito dos processos mais gerais de engajamento pela ampliação dos direitos sociais. 0 surgimento, naquele momento, de partidos, movimentos sociais e sindicais de caráter nacional orientava boa parte das lutas pela ocupação do Estado e projetava esse processo de acúmulo de forças para mudanças institucionais dentro de um campo democrático-popular.

$\mathrm{Na}$ busca pela legalização de suas atividades no período de reabertura política, muitos dos grupos que desenvolviam experiências comunitárias e de educação popular se institucionalizam como associações, institutos e outros tipos de organizações, que 
juridicamente se enquadravam como entidades privadas de caráter social. Sergio Haddad (2014) aponta a formação de ONGs brasileiras já nos anos 1970, muitas delas ligadas às Igrejas e com ligações às entidades do mesmo tipo na Europa, que ofereciam apoio para dar continuidade a projetos populares cercados pela ditadura. Não obstante, dentre o número total de ONGs existentes em 2005 no Brasil, apenas 4\% nasceram nessa década e 22\% ainda nos anos 1980, de acordo com Neves (2005). 0 crescimento mais significativo deu-se a partir dos anos 1990, década na qual mais de 50\% das ONGs foram criadas e, naquele momento, partindo de outros projetos políticos e mais ligadas ao próprio Estado e classes dominante do que a projetos populares (NEVES, 2005). Nos anos 1990, aconteceu o boom das ONGs (SIEIRO FERNANDES; AROEIRA GARCIA, 2008), e não por acaso foi naquele mesmo momento em que surgiu, no Brasil, a educação não formal como campo de pesquisa (AROEIRA GARCIA, 2007).

No início dos anos 1990, as ONGs já aparecem nas leis como "promotoras dos direitos sociais", como é o caso do Estatuto da Criança e do Adolescente (BRASIL, 1990), ou em âmbito internacional, como na Declaração Mundial de Educação para Todos (ou Declaração de Jontiem, também de 1990). Esse último documento demonstra um consenso internacional em torno do objetivo de ampliar o raio de ação da educação para sanar a recorrência da exclusão e do insucesso na aprendizagem, por meio da ampliação de agentes sociais considerados educativos, do fortalecimento de alianças com diversos setores sociais, bem como por meio da mobilização de recursos e entidades públicas e privadas, de modo que as ONGs, que realizam educação não formal, estão inseridas nos “princípios de ação” da Declaração:

A realização de ações conjuntas com organizações não-governamentais, em todos os níveis, oferece grandes possibilidades. Essas entidades autônomas, ao mesmo tempo que defendem pontos de vista públicos, independentes e críticos, podem desempenhar funções de acompanhamento, pesquisa, formação e produção de material, em proveito dos processos da educação não-formal e da educação permanente. (UNESCO, 1990, n.p.).

No Brasil, se tais entidades começam a surgir desde baixo, da organização da sociedade civil, e vinculadas às lutas democráticas ainda nos anos 1970 e 1980, nos anos 1990 se inverte e elas passam a ser criadas desde cima, com amplo incentivo do Estado, que abre editais para projetos de prestação de serviços privados com finalidades públicas. Com isso solidifica-se o Terceiro Setor - que reúne a forma de entidade de direito privado, com objetivos ou caráter que passam a ser considerados públicos, porque desenvolvem trabalhos sociais.

Para Montaño (2007), a debilidade do conceito de Terceiro Setor está na aparência da criação de um “"novo' setor que viria dar as respostas que, supostamente, o Estado já não pode dar e que o mercado não procura dar” (MONTAÑO, 2007, p. 54-55). 0 que aparece como novidade não faz mais do que uma gestão pela "transferência de recursos públicos para setores privados”, com o grave ônus de criar uma nova noção de participação política feita pela sociedade civil, "a partir de um conceito vago de movimento social”, que logrou 
substituir boa parte da atuação "do velho militante do movimento social (dos anos 70 e 80) pelo novo militante da ONG (dos anos 90)” (MONTAÑO, 2007, p. 139).

0 plano de governo de Fernando Henrique Cardoso (2008) mencionava privatização de serviços ${ }^{4}$, enquanto o Plano de Reforma do Aparelho de Estado (1995), que questionava o papel do Estado como provedor de serviços públicos, planejou "transferir para o setor público não-estatal estes serviços, através de um programa de 'publicização', transformando as atuais fundações públicas em organizações sociais” (BRASIL, 1995, p. 26). Assim, a criação de entidades de direito privado também passou a se dar desde cima, do Estado, e não da sociedade civil, tomando forma de programas governamentais, como é o caso da Organização Social Alfabetização Solidária e a Comunitas, criadas em 1996, analisadas por Neves (2005).

Entraríamos em outro capítulo da história de dominação da educação das classes populares pela classe dominante se adentrássemos aqui à "conversão mercantil-filantrópica" (FONTES, 2017) da militância democrática organizada em entidades privadas, associada ao imenso crescimento das Fundações e Associações sem Fins Lucrativos (FASFIL). Sob a bandeira da "responsabilidade social empresarial", em um contexto de crescimento do desemprego e do trabalho precário, operou-se o processo de transferência da gestão dos direitos sociais para as entidades privadas, planejadas pelas reformas dos anos 1990 . A lógica mercantil de disputa por recursos para prestar serviços sociais, constituiu um verdadeiro "mercado da cidadania" (ARANTES, 2004), consolidando "uma nova pedagogia da hegemonia" (NEVES, 2005).

Embora as reformas dos anos 1990 tenham desempenhado papel fundamental para criação desse sistema de terceirização dos direitos sociais, é preciso não subestimar a instauração dessa forma social de organização empresarial sobre os serviços sociais educativos em suas estruturas criadas desde o período militar, como alerta Virgínia Fontes (2017). Não por caso "foi justamente a capacidade política de organização daquelas 'pessoas comuns' o alvo primordial do arrastão aterrorizante que recobriu o país a partir de 1964" (ARANTES, 2014, p. 294), assim como não foi acaso que a estrutura estatal montada a partir da reforma adminstrativa de 1967 foi mantida com a reabertura democrática, incorporada à Constituição de 1988 e atualizada pela Reforma Gerencial do Estado dos anos 1990 (ARANTES, 2014, p. 298).

\section{Considerações finais}

A fissura provocada pelo Golpe Militar de 1964 no desenvolvimento de diversas práticas de educação para as classes populares criou, a um tempo, a educação não formal e a íntima associação entre Estado, empresas e sociedade civil. A ruptura produziu uma forma social permanente, que, embora sofra alterações em graus de importância em

4 - "Tornar o governo mais eficaz para gerir o país e prestar os serviços que a população requer, significa, também, racionalizar a máquina pública e reduzir a presença do Estado em áreas onde ela não é mais necessária. 0 processo de privatização será acelerado, mas teremos o cuidado de não somente reforçar o poder regulamentador e fiscalizador do governo, como também, de evitar a formação de monopólios privados" (CARDOSO, 2008, p. 121). 
distintos contextos sociais, acabou por desenhar a forma hegêmonica da educação não formal no Brasil.

A noção crítica de forma social remete-nos aos nexos entre elementos das relações sociais particulares com a totalidade formal do capital. Não é possível analisar qualquer relação social educativa somente a partir dos discursos, pois o conteúdo também está na forma, isto é, nas relações sociais que ela estabelece com Estado, com o financiamento, com educadores, educadoras e educandos. Almerindo Janela Afonso (2001) já havia destacado que a produção teórica da educação não formal não poderia aderir a essa nova forma acriticamente, sobretudo pelo que ela sintetiza de contradições impostas pelo neoliberalismo, exigindo a apreensão rigorosa dos sentidos das supostas liberdade e autonomia que se desenvolviam no interior deste campo.

Ao estudar os objetivos da educação popular tal qual ela se desenvolveu no início dos anos 1960, é possivel identificar claramente a diferença de objetivos com a educação não formal e, deste ponto de vista, dificilmente a educação popular poderia ser considerada como prática que ocorre dentro do campo da educação não formal. Assim, a educação popular só poderia existir como "negação da negação" (BRANDÃo, 1984, p. 37), tanto da foma como do conteúdo da educação não formal, como contra-hegemonia.

A apreensão crítica - histórica e sociológica - da educação não formal torna inteligível um processo de longa data que também transformou as fundações empresariais nos grandes agentes da educação das classes populares atuais, não apenas presidindo as políticas educativas das atuais reformas, mas também controlando efetivamente uma quantidade incomensurável de práticas na formação de crianças e jovens nas periferias das grandes cidades por meio de seus projetos sociais. 0 que perdurou foi, portanto, a tutela privatista e empresarial da formação popular com o desenvolvimento de formas cada vez mais complexas de associação e fusão entre o direito público e o direito privado sob discursos democráticos de defesa dos direitos sociais.

A abertura de debates e interpretações teóricas atuais que essa abordagem histórica permite, pela adesão ou pelo confronto, talvez possa levar-nos a "compreender a política da educação não formal e da educação não formal como política” (TORRES, 1992, p. 215).

\section{Referências}

AFONSO, Almerindo Janela. Educação não formal. In: SIMSON, Olga Von; PARK, Margaret Brandini; SIEIRO FERNANDES, Renata. Educação não formal: cenários da criação. Campinas: Unicamp/CMU, 2001. p. 29-36.

ARANTES, Paulo Eduardo. 1964. In: ARANTES, Paulo Eduardo. 0 novo tempo do mundo. São Paulo: Boitempo, 2014. p. 281-314.

AROEIRA GARCIA, Valéria. A educação não formal como acontecimento. v. 1. 1. ed. Holambra: Setembro, 2015. 477 p.

AROEIRA GARCIA, Valéria. Educação não formal: um mosaico. In: PARK, Margaret Brandini; SIEIR0 FERNANDES, Renata; CARNIECL, Amarildo (org.). Palavras-chave em educação não formal. Holambra: Setembro; Campinas: Unicamp/CMU, 2007. p. 29-52. 
AROEIRA GARCIA, Valéria. 0 papel da questão social e da educação não formal nas discussões e ações educacionais. Revista de Ciências da Educação, Americana, v. 10, n. 18, p. 65-97, 2008.

BRANDÃO, Carlos Rodrigues. A cultura popular e a educação popular: 7 canções de militância pedagógica acompanhadas de enunciados de início e notas ao final. In: BRANDÃO, Carlos Rodrigues (org.). A questão política da educação popular. São Paulo: Brasiliense, 1980. p. 122-135.

BRANDÃO, Carlos Rodrigues. Educação alternativa na sociedade autoritária. In: PAIVA, Vanilda (org.). Perspectivas e dilemas da educação popular. Rio de Janeiro: Graal, 1984. p. 171-202.

BRASIL. Estatuto da Criança e do Adolescente (ECA). Lei n. 8.069/1990. Brasília, DF: Senado Federal:Coordenação de Edições Técnicas, 1990.

BRASIL. MEC. Fundação Movimento Brasileiro de Alfabetização - MOBRAL. Documento base de implantação. Guanabara: MEC, 1971.

BRASIL. Presidente (Fernando Henrique Cardoso). Plano Diretor da Reforma do Aparelho do Estado. Brasília, DF: Presidência da República: Câmara da Reforma do Estado: Ministério da Administração Federal e Reforma do Estado, 1995. 86p. (Documentos da Presidência da República). Disponível em: http://www. biblioteca.presidencia.gov.br/publicacoes-oficiais/catalogo/fhc/plano-diretor-da-reforma-do-aparelho-doestado-1995.pdf. Acesso em: 11 fev. 2020.

CARDOSO, Fernando Henrique. Mãos à obra, Brasil: proposta de governo [online]. Biblioteca Virtual de Ciências Humanas. Rio de Janeiro: Centro Edelstein de Pesquisa Social, 2008. 131 p. Disponível em: https://static.scielo.org/scielobooks/b27wf/pdf/cardoso-9788599662663.pdf. Acesso em: 11 fev. 2020.

COOMBS, Philip Hall. A crise mundial da educação: uma análise de sistemas. São Paulo: Perspectiva, 1976.

DI PIERO, Maria Clara; JÓIA, Orlando; RIBEIRO, Vera Magasão. Visões da educação de jovens e adultos no Brasil. Cadernos Cedes, Campinas, v. 21, n. 55, nov. 2001.

FONTES, Virgínia. Hegemonias. Qual democracia? In: BADARÓ, Marcelo (org.). Estado e formas de dominação no Brasil contemporâneo. Rio de Janeiro: Consequência, 2017. p. 2-7-236.

FREIRE, Paulo. Educação como prática da liberdade. Rio de Janeiro, Paz e Terra, 2006.

FREIRE, Paulo; GUIMARÃES, Sergio. Lições de casa: últimos diálogos sobre educação. Rio de Janeiro, Paz e Terra, 2014.

FREIRE, Paulo. 0 Mobral nasceu para negar meu método e meu discurso. Entrevista concedida à Mariliene Felinto e Mônica Rodrigues da Costa. Folha de São Paulo, 29 maio 1994. Disponível em: https://www1. folha.uol.com.br/fsp/1994/5/29/mais!/13.html. Acesso em: 16 abr. 2019.

GERMAN0, José Willington. As quarenta horas de Angicos. Educação \& Sociedade, Campinas, v. 18, n. 59, p. 391-395, ago. 1997. 
GHANEM, Elie. Educação formal e não formal: do sistema escolar ao sistema educacional. In: ARANTES, Valéria Amorim (org.). Educação não formal: pontos e contrapontos. São Paulo. Summus, 2008. p. 59-86.

GOHN, Maria da Glória. Educação não formal: um novo campo de atuação. Revista Ensaio, Rio de Janeiro, v. 6, n. 21, 1998.

GOHN, Maria da Glória. Educação não formal e o educador social. São Paulo: Cortez, 2009.

GOHN, Maria da Glória. Educação não-formal na pedagogia social. In: CONGRESSO INTERNACIONAL DE PEDAGOGIA SOCIAL, 1., 2006, São Paulo. Anais online... São Paulo: FEUSP, 2006. Disponível em: http:// www.proceedings.scielo.br/scielo.php?script=sci_arttext\&pid=MSC0000000092006000100034\&lng=e n\&nrm=abn. Acesso em: 12 fev. 2021.

HADDAD, Sérgio. Paulo Freire e o papel das agências de cooperação europeias no apoio à educação popular no Brasil. Pro-Posições, Campinas, v. 25, n. 3 (75), p. 123-141, set./dez. 2014.

MARQUES, Joana Brás Varanda; FREITAS, Denise de. Fatores de caracterização da educação não formal: uma revisão da literatura. Educação e Pesquisa, São Paulo, v. 43, n. 4, p. 1087-1110, dez. 2017.

MONTAÑO, Carlos Eduardo. Terceiro setor e questão social: crítica ao padrão emergente de intervenção social. 4. ed. São Paulo: Cortez, 2007.

NEVES, Maria Lucia Wanderley. A sociedade civil como espaço estratégico de difusão da nova pedagogia da hegemonia. In: NEVES, Maria Lucia Wanderley (org.). A nova pedagogia da hegemonia: estratégias do capital para educar o consenso. São Paulo: Xamã, 2005. p. 85-125.

PAIVA, Vanilda. Introdução. In: PAIVA, Vanilda (org.). Perspectivas e dilemas da educação popular. Rio de Janeiro: Graal, 1984. p. 06-44.

PALHARES, José Augusto. Quarenta anos na sombra da crise da escola: possibilidades e contrariedades no percurso da educação não-escolar. In: COLÓQUIO DA SECÇÃO PORTUGUESA DA AFIRSE XV, 15., 2007. Complexidade: um novo paradigma para investigar e intervir em educação? Actas...[S. I.: s. n.], 2007. Disponível em: https://core.ac.uk/download/pdf/55610924.pdf. Acesso em 11 fev. 2021.

PARK, Margareth Brandini; SIEIRO FERNANDES, Renata; CARNICEL, Amarildo. Palavras-chave em educação não formal. Holambra: Setembro; Campinas: Unicamp/CMUm, 2007.

SCHWARZ, Roberto. Cultura e Política 1964-1968: alguns esquemas. In: SCHWARZ, Roberto. 0 pai de família e outros estudos. Rio de Janeiro: Paz e Terra, 1978. p. 61-92. (Literatura e teoria literária; v. 27).

SADER, Eder. Quando novos personagens entram em cena: experiências e lutas dos trabalhadores da grande São Paulo 1970-1980. Rio de Janeiro: Paz e Terra, 1988.

SIMSON, Olga Rodrigues de Moraes von; PARK, Margareth Brandini; SIEIRO FERNANDES, Renata. Educação não formal: cenários da criação. Campinas: Unicamp/CMU, 2001. 
TORRES, Carlos Alberto. A política da educação não-formal na América Latina. Rio de Janiero: Paz e Terra, 1992.

TRILLA, Jaume. La educación fuera de la escuela: âmbitos não formais e educação social. Barcelo: Ariel, 2003.

UNESCO. Conferência Internacional sobre a Crise Mundial da Educação. Revista Brasileira de Estudos Pedagógicos, Brasília, DF, v. 48, n. 108, p. 305-312, out./dez. 1967.

UNESCO. Declaração mundial sobre educação para todos - Plano de ação para satisfazer as necessidades básicas de aprendizagem. Jomtien, Tailândia 5 a 9 de março de 1990. Disponível em: https://www.unicef. org/brazil/declaracao-mundial-sobre-educacao-para-todos-conferencia-de-jomtien-1990. Acesso em: 11 fev. 2020.

WEFFORT, Francisco C. Educação e política: reflexões sociológicas sobre uma pedagogia da liberdade (prefácio). In: FREIRE, Paulo. Educação como prática da liberdade. Rio de Janeiro: Paz e Terra, 2006.

Recebido em: 27.04.2019

Revisado em: 24.03.2020

Aprovado em: 28.04.2020

Carolina Catini é formada em pedagogia (2004), mestre (2008) e doutora (2013) em Educação pela Faculdade de Educação da Universidade de São Paulo (FEUSP). É professora da Faculdade de Educação da Universidade Estadual de Campinas (Unicamp) e pesquisadora do Grupo de Estudos e Pesquisas Educação e Crítica Social (GEPECS). 